\title{
Distribuição geográfica de uma população disjunta de Herpsilochmus sellowi Whitney \& Pacheco, 2000 (Aves, Thamnophilidae) e implicações para a conservação das fisionomias de carrascos quartzarênicos do médio rio Tocantins, bioma Cerrado, Brasil central \\ Geographical distribution of a disjunct population of Herpsilochmus sellowi Whitney \& Pacheco, 2000 (Aves, Thamnophilidae) and implications for the conservation of the physiognomies of quartzarenic carrascos from the middle Tocantins river, Cerrado biome, Central Brazil
}

\author{
Tulio Dornas' (1) | Ricardo Flores Haidar"ll (1) | Fernando de Morais' (10 \\ Universidade Federal do Tocantins. Programa de Pós-Graduação em Ciências do Ambiente. Palmas, Tocantins, Brasil \\ "Instituto de Desenvolvimento Rural do Tocantins. Palmas, Tocantins, Brasil
}

\begin{abstract}
Resumo: O chorozinho-da-caatinga (Herpsilochmus sellowi) é amplamente distribuído no Nordeste brasileiro, com populações disjuntas no médio rio Tocantins e na serra do Cachimbo, regiões central e sul dos estados de Tocantins e Pará, respectivamente. A população disjunta do médio rio Tocantins ocorre em vegetação arbórea-arbustiva adensada, sobre solo bastante arenoso, sendo comparada às campinaranas amazônicas; localmente é chamada de carrasco. A Área de Ocupação (AOO) e a Extensão de Ocorrência (EOO) de H. sellowi do médio rio Tocantins não ultrapassava 2.500 e 5.000 ha, respectivamente. Apresentamos 20 novos registros da espécie na região central do estado do Tocantins, ampliando a distribuição geográfica desta população para uma AOO de 18.254 ha e uma EOO de 49.600 ha, amenizando o grau de ameaça de extinção regional da espécie. Reiteramos, ainda, que os enclaves de carrascos e campinaranas sobre solos arenosos com H. sellowi sejam definidos como zona de preservação/conservação no zoneamento da Área de Proteção Ambiental (APA) Estadual Lago de Palmas. Recomendamos que as demais áreas identificadas no perímetro de estudo sejam convertidas em outras categorias de unidades de conservação, assegurando a proteção mais ampla desta população de H. sellowi, bem como da singular vegetação e dos elementos paisagísticos presentes e carentes de estudos.
\end{abstract}

Palavras-chave: Bioma Cerrado. Chorozinho-da-caatinga. Enclaves de campinaranas. Vegetação de carrasco. Rio Tocantins. Solos quartzarênicos.

Abstract: Caatinga Antwren (Herpsilochmus sellowi) is widely distributed in northeastern Brazil with disjunct populations: on the Middle Tocantins river (Tocantins state) and Serra do Cachimbo (Pará state). The Middle Tocatins river disjunct population occurs in dense tree-shrub vegetation, on very sandy soil, being comparable with Amazonian campinaranas, locally called carrasco. The Area of Occupation (AOO) and Extent of Occurrence (EOO) of $\mathrm{H}$. sellowi in this area did not exceed 2,500 and 5,000 ha, respectively. We present 20 new records of the species in the central region of Tocantins state, expanding the geographic distribution of this population to an $\mathrm{AOO}$ of $18,254 \mathrm{ha}$ and $\mathrm{EOO}$ of $49,600 \mathrm{ha}$, decreasing the degree of threat of regional extinction of the species. We reiterate that the carrascos and sandy soil campinarinas vegetation enclaves with $H$. sellowi be defined as a preservation/conservation zone in the zoning of the APA Lago de Palmas sustainable use protected area. We recommend that the other identified areas in the perimeters we studied be converted into other categories of protected areas, ensuring the broadest protection of this population of $\mathrm{H}$. sellowi, as well as the unique vegetation and landscape elements that demand study.

Keywords: Cerrado biome. Caatinga Antwren. Campinaranas enclaves. Carrasco vegetation. Tocantins river. Quartzarenic soils.

DORNAS, T., R. F. HAIDAR \& F. MORAIS, 2021. Distribuição geográfica de uma população disjunta de Herpsilochmus sellowi Whitney \& Pacheco, 2000 (Aves, Thamnophilidae) e implicações para a conservação das fisionomias de carrascos quartzarênicos do médio rio Tocantins, bioma Cerrado, Brasil central. Boletim do Museu Paraense Emílio Goeldi. Ciências Naturais 16(1): 21-32. DOI: http://doi. org/10.46357/bcnaturais.v16i1.300.

Autor para correspondência: Tulio Dornas. Universidade Federal do Tocantins. Campus de Palmas. Avenida NS 15, Quadra 109 Norte, Bloco Prof. Lamadrid, Sala 13. Palmas, TO, Brasil. CEP 77001-090 (tuliodornas@yahoo.com.br).

Recebido em 13/04/2020

Aprovado em 06/09/2020

Responsabilidade editorial: Adriano Oliveira Maciel
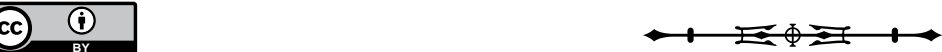


\section{INTRODUÇÃO}

O chorozinho-da-caatinga, Herpsilochmus sellowi, é uma espécie de ave passeriforme da família Thamnophilidae, com ampla ocorrência no Nordeste brasileiro e no norte do estado de Minas Gerais. Além dessas regiões, existem confirmações de populações disjuntas da espécie na região central do estado do Tocantins (Barbosa et al., 2012) e na região da serra do Cachimbo, no sudoeste do estado do Pará (Whitney et al., 2000; Pacheco \& Olmos, 2005; Santos et al., 2011). Análises comparativas morfológicas, acústicas e genéticas destas populações seguem em andamento (Pablo V. Cerqueira, comunicação pessoal, 2019).

Descrita há 20 anos, H. sellowi advém de populações anteriormente identificadas como $\mathrm{H}$. pileatus, tendo como diagnose específica variações na plumagem e em caracteres morfológicos e vocais (Whitney et al., 2000). Em âmbitos nacional (MMA, 2014) e global (Birdlife International, 2016), H. sellowi é categorizada como pouco preocupante em relação ao risco de ameaça de extinção. Contudo, presumese uma tendência atual de declínio populacional da espécie, baseada na população ocorrente no Nordeste brasileiro e no norte de Minas Gerais (Birdlife International, 2016).

O habitat da espécie varia entre formações arbóreas de Caatinga, matas de cipós na transição Caatinga e Mata Atlântica, florestas semideciduais e deciduais nas regiões do oeste da Bahia e norte de Minas Gerais, respectivamente; enquanto no litoral do Nordeste está presente em vegetação de restingas (Whitney et al., 2000). Na serra do Cachimbo, ocorre em vegetação de campinaranas e savanas arborizadas (Pacheco \& Olmos, 2005; Santos et al., 2011).

No estado do Tocantins, H. sellowi foi recentemente encontrada em área coberta por savanas e florestas sobre solo arenoso (Neossolo Quartzarênico), na margem esquerda do rio Tocantins, no município de Porto Nacional (Barbosa et al., 2012). Moreira (2017) verificou a permanência da população na mesma região cinco anos depois, com novos registros em um ponto afastado $3 \mathrm{~km}$ da área original da descoberta. Nesta região, a geomorfologia é composta por formas de relevo convexas, com vales de fundos planos e feições tabulares com distintos níveis de incisão fluvial. Apresenta também superfícies pediplanadas da borda oeste da bacia do Parnaíba, caracterizando o Planalto do Interflúvio Araguaia-Tocantins (Brasil, 1981).

A estrutura da vegetação do local é semelhante às campinaranas amazônicas, sobretudo aquelas onde H. sellowi é encontrada. Regionalmente, moradores denominam essa vegetação como carrasco baixo (tipo de savana arborizada) e carrasco alto (floresta estacional semidecídua), nomenclatura também adotada em inventários florestais no norte do Tocantins (Olmos et al., 2004; Dambrós et al., 2005; Haidar et al., 2013).

Dessa maneira, desde a sua descoberta no estado do Tocantins, em 2012, H. sellowi é conhecida a partir de três ou quatro localidades, as quais, quando somadas as suas áreas, não atingem 5.000 ha, conforme cálculos realizados no software Google Earth Pro (GEPro). Essa área de ocorrência diminuta caracteriza uma das menores distribuições geográficas entre as aves conhecidas no estado do Tocantins, refletindo um status de conservação bastante preocupante para a espécie em âmbito estadual.

Portanto, o objetivo deste estudo foi apresentar uma nova e mais ampla distribuição geográfica da espécie em território tocantinense, com base em novas expedições realizadas em diferentes localidades no estado. Foram indicados novos dados de Área de Ocupação (AOO) e de Extensão de Ocorrência (EOO) e discutido o status de conservação estadual da espécie. Por fim, foram discutidas ações de conservação da vegetação de campinaranas/ carrasco sobre solos arenosos presentes na região.

\section{MATERIAL E MÉTODOS}

\section{ÁREA DE ESTUDO}

A cobertura vegetal da área de estudo compreende formações de savana arborizada, em mosaico com florestas estacionais semideciduais estabelecidas sobre solos bastante arenosos (Neossolo Quartzarênico), presentes nos limites dos municípios de Porto Nacional e Miracema do Tocantins, 
imediatamente à margem esquerda do rio Tocantins (Figura 1). Essas formações florestais foram classificadas como campinaranas ou carrascos, por Olmos et al. (2004), por apresentarem semelhança florística com manchas de florestas que ocorrem nas áreas de contato do Cerrado com a Amazônia no norte do Tocantins, onde há predomínio da espécie arbórea Callisthene minor Mart. (Haidar et al., 2013).
Essa espécie é predominante nas formações de carrascos/ campinaranas da área de estudo, associada a espécies comuns típicas de formações de savana, como Copaifera coriacea Mart., Dimorphandra gardneriana Tul., Qualea parviflora Mart., Kielmeyera coriacea Mart. \& Zucc., Hymenaea eriogyne Benth., Kielmeyera lathrophyton Saddi e Cenostigma macrophyllum Tul. (Haidar et al., 2013).

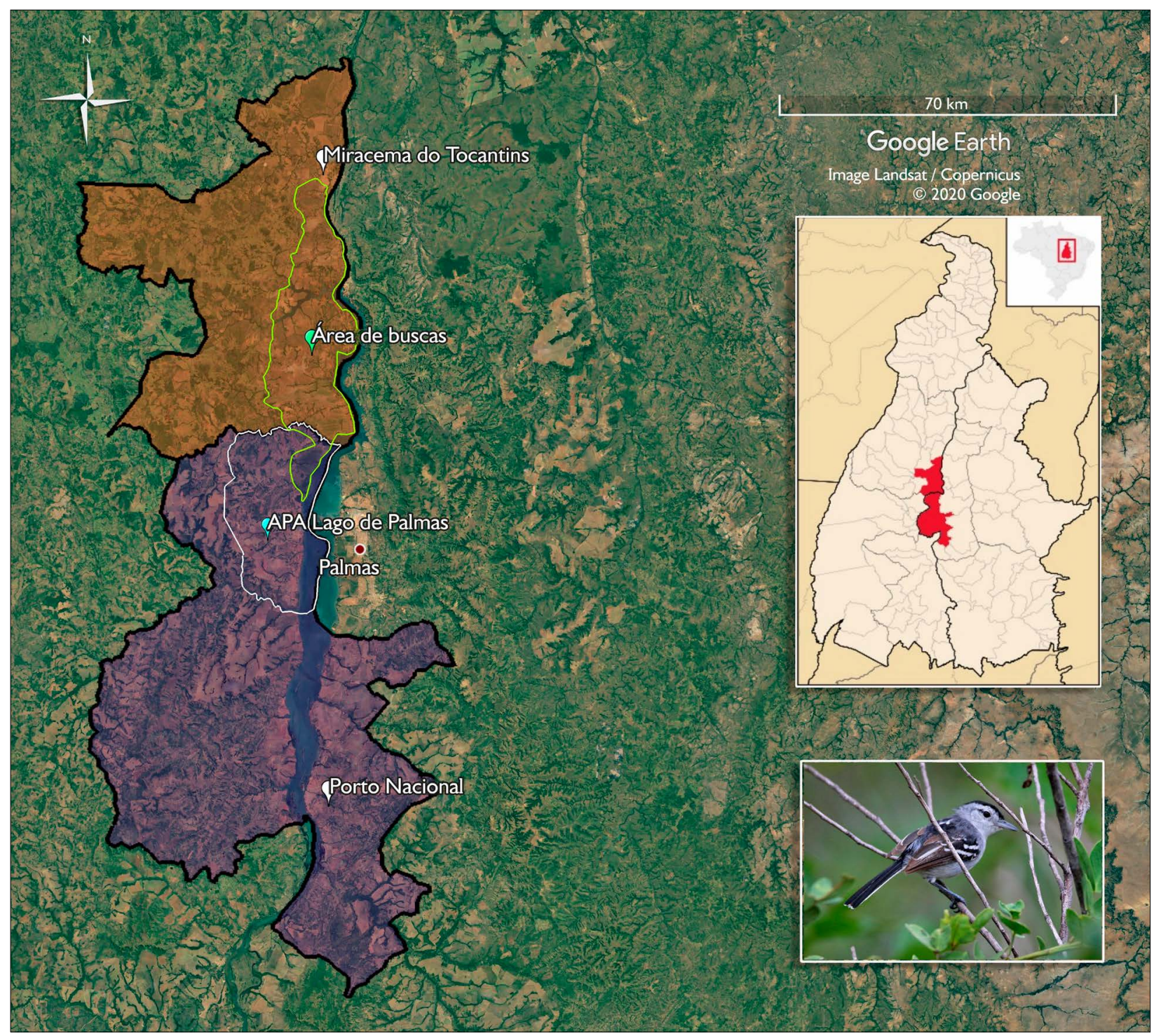

Figura 1. Área de buscas (polígono de linha verde) por Herpsilochmus sellowi na região do médio rio Tocantins, no estado do Tocantins. Áreas em roxo e laranja representam os municípios de Porto Nacional e Miracema do Tocantins, respectivamente. O polígono de linha branca mostra o limite da APA do Lago de Palmas (APALP), cujo limite norte trata-se do ribeirão Santa Luzia, o qual é também limite de ambos os municípios. Fonte: Google Earth Pro. Foto: Tulio Dornas.

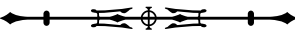


A região de estudo se estende, ainda, perpendicularmente da margem do rio Tocantins para oeste, em aproximadamente $15 \mathrm{~km}$, e no sentido norte-sul segue desde a sede municipal de Miracema do Tocantins até a confluência do córrego Capivara com o reservatório da Usina Hidrelétrica (UHE) Luís Eduardo Magalhães, mas também conhecida e tratada neste estudo como UHE de Lajeado, no munícipio de Porto Nacional. Os principais corpos d'água e afluentes do rio Tocantins na região são: córregos Capivara e Sapezal, e os ribeirões Santa Luzia, Gameleira e Correntinho (SEPLAN, 2012).

A mata ciliar e parte significativa da vegetação nativa adjacente ao rio Tocantins encontram-se submersas à montante do ponto de barramento do reservatório da UHE de Lajeado (SEPLAN, 2012). À jusante do ponto de barramento, as margens do rio Tocantins e a vegetação nativa ainda são encontradas em diferentes níveis de conservação (SEPLAN, 2012).

O clima regional, úmido ou subúmido, possui duas estações bem definidas, uma seca e outra chuvosa, com a pluviosidade média local variando entre 1.700 a $1.900 \mathrm{~mm}$ e temperatura média entre 26 e $27^{\circ} \mathrm{C}$, com máximas podendo superar os $40^{\circ} \mathrm{C}$ (SEPLAN, 2012). Geomorfologicamente, a região é o limite oeste da Bacia Sedimentar do Parnaíba, inserida na depressão do médio rio Tocantins. A altitude local varia entre 150 a 400 metros, com altitude mínima na margem do rio Tocantins (SEPLAN, 2012).

Os solos da região estão distribuídos em um mosaico entre Neossolos Quartzarênicos órticos, Latossolos Vermelhos-Amarelos distróficos e Plintossolos Pétricos concrecionários (IBGE, 2007; SEPLAN, 2012). As buscas por $\mathrm{H}$. sellowi ocorreram predominantemente nas áreas de Neossolos Quartzarênicos, devido a seu caráter arenoso, onde se concentram as formações vegetais de carrascos/campinaranas.
A porção sul da área de estudo está inserida no limite norte da Área de Proteção Ambiental (APA) Lago de Palmas, unidade de conservação estadual de uso sustentável com aproximadamente 51.000 ha (SEPLAN, 2012; SEFAZ, 2019). O novo e revisado plano de manejo foi apresentado ao conselho gestor da Unidade de Conservação em dezembro de 2019, no entanto não se encontra publicado segundo comunicado oficial disponível no portal do Instituto Natureza do Tocantins (Naturatins)'.

\section{PROCEDIMENTOS}

Os registros de Herpsilochmus sellowi ocorreram de forma ocasional entre os anos de 2012 e 2018, por meio de prospecções aleatórias durante atividades de observação de aves nos municípios de Porto Nacional e Miracema do Tocantins. Contudo, entre setembro de 2019 e fevereiro de 2020, pelo menos três buscas focadas na espécie foram conduzidas em diferentes áreas de campinaranas/carrascos e savanas arborizadas sobre solos arenosos, na margem esquerda do rio Tocantins, município de Miracema do Tocantins.

Registros que tiveram fotografias e/ou gravação sonora foram depositados nos portais de WikiAves (s. d.) e/ou Xeno-canto (s. d.). Foram realizados censos ocasionais para tomar ciência da abundância local da espécie em algumas das localidades de buscas, nas primeiras horas da manhã (06h00 a 08h00), em trilhas lineares, com aproximadamente 1.000 metros e com largura estimada de 100 metros (portanto, equivalente à área de 10 ha).

Os locais de busca selecionados para prospecções foram determinados com base em imagens de satélites, disponibilizadas pelo software gratuito Google Earth PRO (GEPro), e nas cartas geológicas e pedológicas Miracema do Norte (SC-22-X-D) e Porto Nacional (SC-22-Z-B), disponibilizadas nos acervos geológicos online do IBGE (s. d.) e CPRM (s. d.). Foram selecionados pontos de buscas em localidades cujas imagens de satélites, combinadas às

Disponível em https://naturatins.to.gov.br/conselho-da-area-de-protecao-ambiental-do-lago-de-palmas-conselho-da-apa-do-lago-depalmas/agenda-de-reunioes/. 
feições representadas por solos ou litografia nas referidas cartas, permitiram interpretar, na paisagem, a combinação de solos arenosos (quartzarênicos) e vegetação arbórea do tipo campinarana/carrasco, semelhante às regiões onde existem pontos da espécie já conhecidos.

Os pontos de buscas com êxito na detecção de H. sellowi foram plotados no GEPro. Em seguida, com base nos pontos plotados, foram delineados polígonos que abrangessem todo o habitat da espécie circundante ao ponto de detecção. As medidas em hectares resultantes dos polígonos esboçados foram utilizadas para estimar os tamanhos da Área de Ocupação (AOO) e da Extensão de Ocorrência (EOO) desta população disjunta de H. sellowi do médio rio Tocantins, conforme definição e critérios estabelecidos pela IUCN (2019) e pelo ICMBio (2013).

As datas de captação das imagens interpretadas, disponibilizadas pelo GEPro, ocorreram entre os períodos de 19 de julho de 2017 a 11 de junho de 2019, demostrando serem contemporâneas às condições naturais e antrópicas do momento das buscas. As validações da cobertura vegetal e do uso da terra dos pontos visitados e dos polígonos delineados se deram durante as expedições em campo.

\section{RESULTADOS E DISCUSSÃO}

Foram efetuados 20 novos registros de Herpsilochmus sellowi ao longo da área de estudo. Em 2016, foram realizados os primeiros registros da espécie no município de Miracema do Tocantins (Dornas, 2016a, 2016b), em área de vegetação de campinarana/carrasco (porte arbóreo-arbustivo, adensada, em solo arenoso, 9 58' 38" S; 4829' 18" O), tal como a descrita no local onde a espécie foi descoberta no estado por Barbosa et al. (2012). Moreira (2017) conduziu um inventário avifaunístico nos limites da APA do Lago de Palmas, registrando $H$. sellowi em um novo ponto (104' 40" S; 48 24' 36" O), distando aproximadamente $10 \mathrm{~km}$ da localidade descrita por Barbosa et al. (2012), ambos no interior do munícipio de Porto Nacional, à margem direita do ribeirão Santa Luzia.
Desde então, somente essas três localidades têm sido as referências de ocorrência da espécie no estado do Tocantins, uma vez que levantamentos ornitológicos conduzidos em vegetação de campinarana/carrasco no norte do Tocantins não detectaram a espécie (Olmos et al., 2004; Dornas et al., 2012; Dornas, 2016c). Portanto, considerando os registros conhecidos de $\mathrm{H}$. sellowi entre 2012 e 2017 no Tocantins, a AOO da espécie não ultrapassava $2.500 \mathrm{ha}\left(25 \mathrm{~km}^{2}\right)$, enquanto a EOO era pouco mais de 5.000 ha $\left(50 \mathrm{~km}^{2}\right)$. A distância em linha reta entre os pontos de ocorrência mais extremos era de $18 \mathrm{~km}$. Estes valores de $\mathrm{AOO}$ e EOO são extremamente reduzidos e sinalizam cenário severamente susceptível a processos de antropização, colocando a espécie em um status de conservação criticamente em perigo em âmbito estadual.

Diante dos registros existentes e dos 20 registros novos efetuados ao longo dos municípios de Porto Nacional e Miracema do Tocantins, pode-se afirmar que a $\mathrm{AOO}$ e a EOO da espécie aumentaram significativamente. Os novos cálculos demonstram uma $\mathrm{AOO}$ de 18.254 ha (182,54 km²) e uma EOO de 49.600 ha (496 km²) (Figura 2).

A partir deste novo cenário, a distância anteriormente indicada de $18 \mathrm{~km}$ entre as localidades extremas de registros se estende para mais de $60 \mathrm{~km}$. Considerando que as interpretações das imagens do GEPro demonstraram, na região, a existência de outros grandes blocos de adensadas campinaranas/carrascos sobre solos arenosos, presume-se que a $\mathrm{AOO}$ para $H$. sellowi nesta porção média do rio Tocantins ainda poderá ter um aumento, com potencial de atingir até 22.500 ha $\left(225 \mathrm{~km}^{2}\right)$.

Segundo a aplicação dos critérios de ameaça de extinção definidos pela IUCN (2019), os valores de EOO e AOO encontrados (respectivamente, $496 \mathrm{~km}^{2}$ e 182,54 km²) categorizam H. sellowi, para os limites do estado do Tocantins, como 'em perigo de extinção'. Essa categoria de ameaça é definida pelos critérios B1 (EOO $<5.000$ km²) e/ou B2 b(iii), c(iv) (AOO $<500 \mathrm{~km}^{2}$, com declínio continuado na sua área, extensão e/ou qualidade de habitat e devido a flutuações extremas no número de indivíduos maduros). 

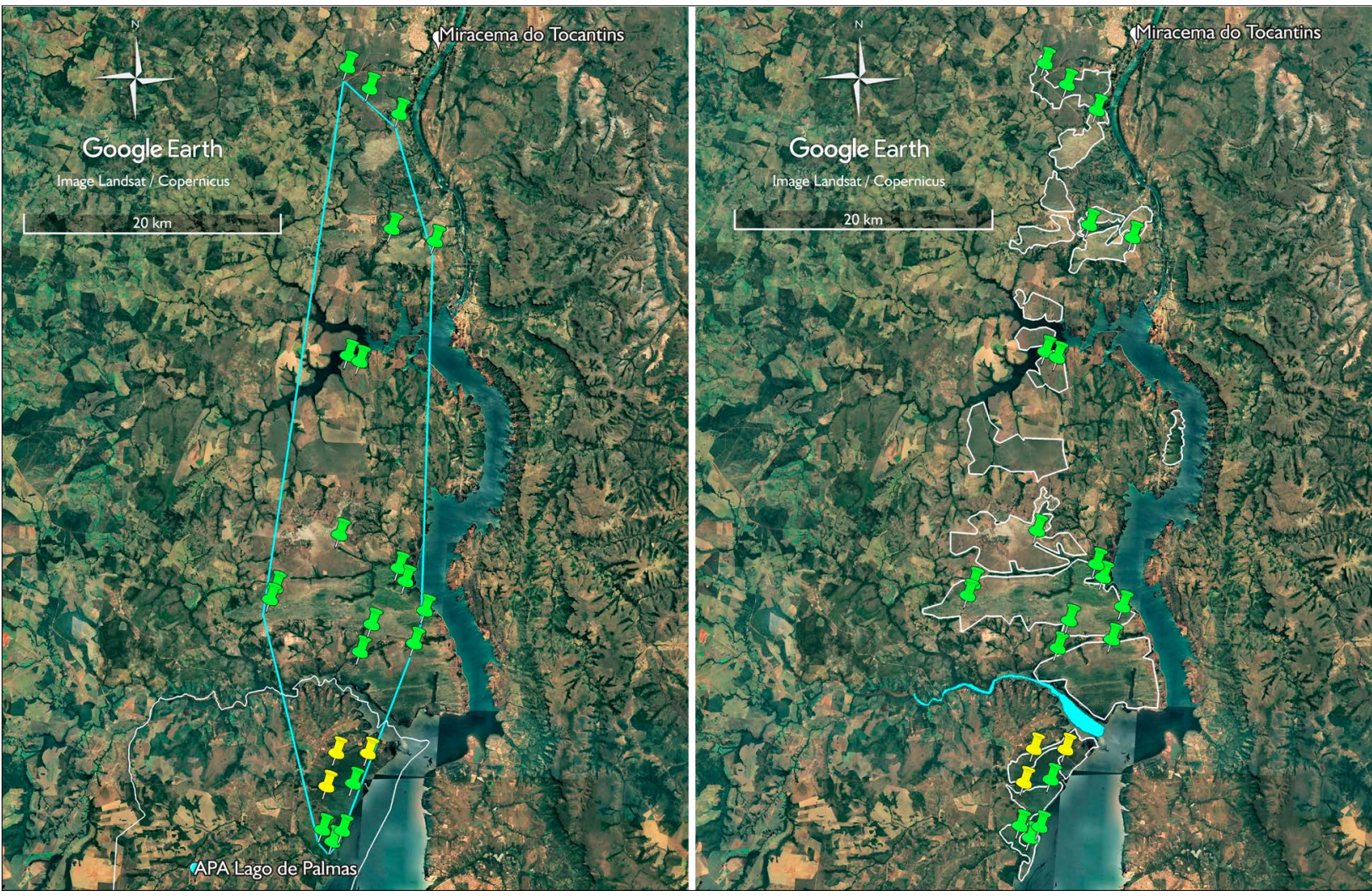

Figura 2. Limites da Extensão de Ocorrência (EOO) e Área de Ocupação (AOO) de Herpsilochmus sellowi no estado do Tocantins. Os pontos de registros verdes representam registros da espécie realizados a partir de 2017; e os pontos amarelos representam registros conhecidos anteriormente (Barbosa et al., 2012; Moreira, 2017). À esquerda, o polígono de linha azul representa a EOO. À direita, os polígonos de linha branca representam a $\mathrm{AOO}$, de modo que em polígonos ausentes de registros é presumida a ocorrência de $H$. sellowi. O polígono sólido em azul representa o ribeirão Santa Luzia.

Os censos de H. sellowi detectaram de 8 a 12 casais, ou seja, uma densidade média de dez casais a cada 10 ha ou um casal/ha. Considerando a AOO estimada de 18.254 ha, a abundância da espécie ao longo da região de estudo pode chegar a 36.500 indivíduos. Este contingente populacional está acima dos limiares mínimos considerados pela IUCN (20.000 indivíduos) para que haja o enquadramento em alguma categoria de ameaça segundo o critério de tamanho populacional (IUCN, 2019).

A perda e a degradação dos habitats da espécie na região, concomitantemente ao reduzido tamanho da sua $\mathrm{AOO}$, podem incidir, a médio e longo prazo, em uma taxa de declínio populacional expressiva, pois o elevado contingente populacional estimado está presente em uma pequena área geográfica. A expansão imobiliária, com a demarcação e a abertura de chacreamentos e condomínios residenciais em áreas de campinaranas/carrascos entre os córregos Santa Luzia e Capivara, ocorre desde o enchimento do reservatório da UHE do Lajeado e tem sido mais intensa nos últimos dez anos (Pinto, 2014).

Além dos grandes blocos de campinaranas/carrascos inseridos nos limites da APA do Lago de Palmas (Moreira, 2017), dentro do perímetro de estudo ainda se concentram áreas superiores a 3.000 ha, entre as quais destacam-se dois pontos onde a espécie foi detectada, ambos localizados a norte do ribeirão Santa Luzia, com, respectivamente, 3.826 e 5.390 ha, em uma região conhecida como 'Tombador de Areia da Lagoa Feia'. Devido às suas grandes dimensões em

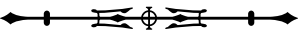


hectares e à sua integridade ambiental, esses pontos podem ser elencados como áreas prioritárias para conservação de $H$. sellowi, e de toda biodiversidade e geodiversidade associadas nesta região (Figura 2).

As recomendações propostas por Moreira (2017) quanto à definição de que toda extensão de campinaranas/ carrascos da porção norte da APA do Lago de Palmas seja considerada como zona de preservação/conservação são profundamente aguardadas na revisão do plano de manejo desta UC. Apesar dos estudos de revisão do plano de manejo não estarem disponíveis para consulta, são evidentes a espera por sua oficialização por parte do poder executivo e a relevância biológica da área, em função da singularidade biogeográfica e da presença de espécies ameaçadas de extinção e endêmicas.

Os valores em hectares de $\mathrm{AOO}$ e EOO de $\mathrm{H}$. sellowi apresentados no presente estudo reforçam a proposição de Moreira (2017) sobre a necessidade de maior preservação destas fitofisionomias. A perda de cobertura vegetal nativa ao longo dos limites da APA do Lago de Palmas foi de aproximadamente 45\% entre 2000 e 2015 (Moreira, 2017). Ademais, Oliveira et al. (2019) apresentaram percentuais similares, com 39\% da cobertura vegetal da APA do Lago perdidos entre 2000 e 2017 por desmatamento e urbanização, enquanto outros 18\% foram decorrentes da inundação da vegetação nativa pelo enchimento do reservatório da UHE de Lajeado.

Fora da APA do Lago de Palmas, a partir da margem esquerda do ribeirão Santa Luzia até a sede municipal de Miracema do Tocantins, o desmatamento para cultivo de eucalipto representa uma grande ameaça à conservação de H. sellowi. O solo predominantemente arenoso impede atividades de pecuária e agricultura de grãos na região e, como alternativa, tem sido buscado o emprego do plantio de eucalipto nas áreas de campinaranas/carrascos suprimidas.

A região de Miracema do Tocantins apresenta aptidões climáticas e edáficas para cultivo de eucalipto entre níveis aceitáveis e marginais (Souza et al., 2015). No entanto, ao longo dos últimos cinco anos, foram notadas duas situações em campo: 1) áreas suprimidas para atividade de silvicultura nunca tiveram o plantio das mudas consolidadas; 2) notou-se um aparente aspecto de abandono nas áreas de plantio, com galhos e ramos desfolhados e o sub-bosque tomado por espécies daninhas, arbustos e herbáceas. Essas situações parecem ser respostas às tendências de queda do mercado de silvicultura dos últimos anos, provocando desinteresse na produção de eucalipto na região central e sul do Tocantins (Castro et al., 2019).

Outra importante ameaça à população de $H$. sellowi, no médio rio Tocantins, é o incêndio ilegal. Visitas à região no período seco, nos anos de 2017 e 2018, e em algumas das áreas selecionadas no período seco de 2019, sobretudo entre os meses de agosto e outubro, possibilitaram a constatação de incêndios severos incidindo sobre a vegetação nativa. Além das observações diretas em algumas localidades, o monitoramento realizado pelo Programa Queimadas do Instituto Nacional de Pesquisas Espaciais (INPE) apontou a ocorrência de inúmeras queimadas nos municípios de Miracema do Tocantins e Porto Nacional nos períodos secos dos anos que observamos, nas áreas que abrigam H. sellowi (INPE, 2018).

Próximo ao ribeirão Santa Luzia, no município de Miracema do Tocantins, foram registrados cinco casais da espécie em uma área de 500 metros de raio em campinaranas/carrascos, onde se verificou a passagem de incêndios florestais entre as estações secas de 2018/2019. Tais registros sugerem a capacidade de resiliência da espécie à passagem do fogo e sua persistência em áreas em processo de recuperação vegetacional.

Devido às condições de seca extrema da vegetação de campinarana/carrasco no auge do período de estiagem, uma desastrosa combinação de incêndios florestais de grandes proporções pode queimar parcela representativa destes 18.254 ha de AOO estimados para a espécie. Vale ressaltar que os blocos de campinaranas/carrascos estão fragmentados pelos leitos inundados dos ribeirões Santa Luzia e Gameleira, ou por vales úmidos de pequenos 
ribeirões locais, com densas matas de galeria, os quais podem evitar ou mesmo conter uma propagação contínua do fogo.

Portanto, duas alternativas devem ser pensadas como formas de melhorar o status de conservação de H. sellowi no Tocantins: em primeiro lugar, estão ações impostas sobre a espécie, como aumentar o conhecimento da sua história natural; em segundo, ações amplas ou sistêmicas numa escala macrorregional, ou seja, investir em medidas de conservação dos ambientes de campinaranas/ carrascos do médio rio Tocantins (e também, de forma preventiva e cautelar, na região norte do estado).

Com relação à ecologia e à história natural, é importante conhecer em detalhes aspectos como tamanho populacional e sucesso reprodutivo. Além disso, expedições de busca pela espécie em outras áreas de mesma fitofisionomia são imprescindíveis. A presença de solos arenosos (Neossolos Quartzarênicos) no Tocantins se estende da região de estudo até o extremo norte do Tocantins (SEPLAN, 2012). As buscas por H. sellowi em áreas potenciais entre Miracema do Tocantins e Porto Nacional, além daquelas conhecidas até 2017, mostraram-se eficientes e foram imprescindíveis para o aumento significativo da $\mathrm{AOO}$ e da EOO da espécie, em âmbito estadual.

Em âmbito estadual, o tamanho de $50 \mathrm{~km}^{2}$ de EOO anterior às buscas realizadas indicaria $H$. sellowi como espécie criticamente ameaçada (CRI); os novos valores de $\mathrm{AOO}$ e EOO apresentados permitiriam, portanto, a mudança de categoria para 'em perigo' (EN). Buscas na região de Ananás e Wanderlândia são prioritárias por serem tratadas como os principais remanescentes de campinaranas/carrascos no norte do Tocantins (Olmos et al., 2004). Novos registros nessa região podem alterar o status de conservação da espécie em âmbito estadual para a categoria de 'ameaça ainda menos severa'.

Olmos et al. (2004) já enfatizavam a necessidade emergencial de proteção desses ambientes com a criação de unidades de conservação. Nas campinaranas/ carrascos de Ananás e Wanderlândia, foi detectada uma avifauna singular, com elementos típicos de campinas e campinaranas do centro-oeste amazônico, como Xenopipo atronitens Cabanis, 1847 (pretinho) e Rhytipterna immunda (Sclater \& Salvin, 1873) (vissiá-cantador) (Olmos et al., 2004; Dornas et al., 2012; Dornas, 2016c), sinalizando potencial semelhante de novidades biogeográficas para outros grupos de vertebrados terrestres.

Igualmente importante tem sido o papel das campinaranas/carrascos do médio rio Tocantins, pois, além de abrigarem integralmente a população de $H$. sellowi da porção central do Brasil, abrigam uma avifauna particular, com presença de elementos florestais amazônicos como Chiroxiphia pareola (Linnaeus, 1766) (tangará-príncipe) e Ornithion inerme Hartlaub, 1853 (poiaeiro-de-sobrancelha), bem como elementos de campinas, como o já citado Rhytipterna immunda, simpátrico ao próprio H. sellowi na região (Dornas et al., 2012). Por estarem circundadas pelas diferentes fitofisionomias de Cerrado em sentido amplo, as campinaranas/carrascos do médio Tocantins compartilham perifericamente aves típicas do bioma Cerrado, como Charitospiza eucosma Oberholser, 1905 (mineirinho) e Celeus obrieni Short, 1973 (pica-pau-do-parnaíba, pica-pau-da-taboca), ambas com status de ameaça bastante preocupantes (MMA, 2014; IUCN, 2019).

Além da importância para as aves, as campinaranas/ carrascos do médio rio Tocantins conferem o caráter de endemismo tocantinense a outras duas espécies de animais, que até o momento só foram encontradas nessa região. As espécies, atualmente consideradas como criticamente ameaçadas de extinção, tanto em âmbito global quanto nacional (MMA, 2014; IUCN, 2019), são Scolopendropsis duplicata Chagas Jr. Edgecombe \& Minelli 2008, uma centopeia (Chagas-Junior et al., 2008), e Bachia psamophila Rodrigues, Pavan \& Curcio, 2007, um lagarto (Rodrigues et al., 2007). Ambas as espécies são contempladas em "Plano de ação territorial estadual para conservação de espécies ameaçadas de extinção" (Tocantins, 2020).

Desta forma, S. duplicata e B. psamophila, juntamente a esta população disjunta de $H$. sellowi, demonstram que as campinaranas/carrascos do médio rio Tocantins possuem 
uma história evolutiva importante na diversificação da fauna neotropical, o que também pode ser constatado sob a ótica florística, devido à ocorrência de Callisthene minor, espécie vegetal comum nas campinaranas/carrascos do Tocantins, que também ocorre em vegetações savânicas similares sobre solos arenosos em outras partes do Brasil central. Do ponto de vista biogeográfico, essa condição eleva substancialmente a relevância desta vegetação e de seus habitats, assim como dos elementos geológicos e litológicos da paisagem, pois sinaliza potencial notável para ainda abrigarem outros organismos animais e/ou vegetais, não descritos cientificamente, com semelhante padrão evolutivo e biogeográfico às espécies citadas.

Portanto, ações de conservação dos ambientes de savanas arenosas da região do médio rio Tocantins podem ser destacadas nas seguintes alternativas:

1) Consolidação das campinaranas/carrascos e das savanas arbóreas sobre solo arenoso como áreas de uso restrito, devendo ser terminantemente aprovado pelo conselho gestor da Área de Proteção Ambiental (APA) Lago de Palmas como zonas de preservação/conservação no zoneamento apresentado no revisado plano de manejo em processo de consolidação, em consonância também com a proposta de Moreira (2017). Esta aprovação, em definitivo, permitirá a proteção legal dessas vegetações e de seu solo arenoso, ficando impedida a sua supressão e retirada para atividades de silvicultura, loteamentos rurais (chacreamentos) e extração/mineração nos limites da APA do Lago de Palmas. Consequentemente, as populações de H. sellowi (e toda biodiversidade associada nos limites da APA) terão seus habitats preservados, garantindo os requisitos ecológicos necessários para manterem suas populações locais;

2) Criação de Unidades de Conservação (UC) do tipo Reservas Particulares do Patrimônio Natural (RPPN) ou o estabelecimento de UC de proteção integral como o Refúgio de Vida Silvestre (REVIS) ou o Monumento Natural (MONA), cuja desapropriação fundiária não é necessariamente obrigatória, desde que decretada em aquiescência entre poderes públicos e proprietários, conforme as legislações vigentes (MMA, 2000; Tocantins, 2005). As categorias citadas de UC podem ser criadas como medidas compensatórias decorrentes da construção da UHE de Lajeado e seu reservatório, ou decorrentes do estabelecimento de linhas de transmissão de alta voltagem, ou empreendimentos silvicultores de grande porte. Vale destacar que as áreas pleiteadas para possíveis unidades de conservação não apresentam vocação para o agronegócio ou para processo de urbanização, o que, geralmente, implica preços de terra comparativamente bastante reduzidos, favorecendo ações de conservação que resultem na proteção de seus limites. Além disso, a criação de UC pode auxiliar na arrecadação municipal, em função das regras de repasse do Imposto sobre Circulação de Mercadorias e Serviços (ICMS) Ecológico Estadual;

3) Estabelecimento de legislação estadual para que os órgãos licenciadores ambientais direcionem e indiquem áreas de campinaranas/carrascos para compensação de reservas legais. Com o estabelecimento do Cadastro Ambiental Rural (CAR), os órgãos licenciadores estaduais e municipais, e até mesmo Ministérios Públicos Estaduais e Federais, sabem quais propriedades apresentam passivos ou ativos de reserva legal. Deste modo, o poder público pode recomendar a compra de áreas de campinaranas/ carrasco do médio rio Tocantins para averbação de reserva legal. Tal atitude garantiria maior agilidade na proteção e contribuiria para melhorar o status de conservação de $\mathrm{H}$. sellowi, assim como os demais elementos da biodiversidade associados a esta porção central do Tocantins.

\section{CONCLUSÃO}

A população do médio rio Tocantins de $H$. sellowi teve sua distribuição geográfica notavelmente ampliada, com suas $\mathrm{AOO}$ e EOO aumentando entre 7 e 10 vezes em relação àquelas até então conhecidas. Com abundância relativamente alta, um casal a cada hectare, o tamanho populacional foi descartado como critério para determinação de seu status de conservação, devendo ser baseado na sua diminuta distribuição geográfica. Em âmbito estadual, eventual processo de avaliação de 
ameaça de extinção deve categorizar $H$. sellowi como 'em perigo', segundo critérios adotados nas avaliações nacional e global de espécies animais. Tal condição atribuiu a $H$. sellowi o título de uma das espécies de aves mais ameaçadas de extinção do estado do Tocantins.

O zoneamento previsto no plano de manejo em revisão para a APA do Lago de Palmas deverá considerar a indicação das campinaranas/carrascos como zonas de conservação/preservação. Desse modo, a população de $H$. sellowi, bem como a diversidade florística e as espécies S. duplicata e B. psamophila, ameaçadas de extinção, serão todas protegidas. Ressalta-se que as duas últimas espécies citadas estão contempladas em "Plano de ação territorial para conservação de espécies ameaçadas de extinção do território Cerrado do Tocantins" (Tocantins, 2020). Contudo, outras áreas ao longo do perímetro de estudo também devem ser alvo da criação de unidades de conservação públicas e/ou privadas.

Grandes blocos de campinaranas/carrascos com tamanhos entre 3.000 e 6.000 ha, como aqueles localizados ao norte do ribeirão Santa Luzia, na região do 'Tombador de Areia da Lagoa Feia', em Miracema do Tocantins, apontam áreas favoráveis à criação de novas unidades de conservação. $O$ solo arenoso, com baixíssima fertilidade e encurtada vocação agropecuária, indica reduzidos preços de mercado, podendo representar oportunidades de aquisição e criação de unidades de conservação, favorecendo parcela significativa da biodiversidade tocantinense.

Por fim, os estudos de sistemática e de biogeografia histórica em andamento podem reconhecer uma eventual diversificação dessa população disjunta de $H$. sellowi, elevando-a até mesmo ao patamar de espécie plena. Todavia, independente desta confirmação, o isolamento geográfico já detectado para H. sellowi, bem como para Scolopendropsis duplicata, Bachia psamophila e Callisthene minor, no médio rio Tocantins demonstra a importância de ações concretas à conservação efetiva destas espécies. Não diferentemente, fica evidente a necessidade de proteção desta particular vegetação de campinarana/carrasco sobre singulares solos arenosos, que escondem histórias evolutivas e geológicas desconhecidas nesta porção do bioma Cerrado, na região central do Brasil.

\section{AGRADECIMENTOS}

Agradecemos aos dois revisores anônimos e ao editor de seção, pelas valiosas contribuições ao manuscrito. Agradecemos, ainda, a André Natale, Dalila Ferreira, Dianes Marcelino, Eduardo Ribeiro, Geoffrey Mcmullan, Gilson Afonso, Leticia Portillo, Luiz Cortez, Ludmilla Weber, Márcio Silveira, Marcelo O. Barbosa, Neander Heming, Renato Soares Moreira e Thiago Filadelfo, pelas companhias em algumas das incursões a campo. Agradecemos a Bennett Hennessey, pelo auxílio na redação do Abstract. TD agradece à Coordenaç̧ão de Aperfeiçoamento de Pessoal de Nível Superior (CAPES), pela bolsa de estágio pós-doutoral do Programa Nacional de Pós-Doutorado (PNPD/CAPES), e ao Programa de Pós-Graduação em Ciências do Ambiente (PPG-CIAMB) da Universidade Federal do Tocantins (UFT), pelo apoio logístico e institucional.

\section{REFERÊNCIAS}

BARBOSA, M. O., J. F. PACHECO \&A. G. CORRÊA, 2012. Primeiro registro de chorozinho-da-caatinga, Herpsilochmus sellowi, no estado do Tocantins, Brasil. Atualidades Ornitológicas 169: 22.

BIRDLIFE INTERNATIONAL, 2016. Herpsilochmussellowi. The IUCN Red List of Threatened Species 2016: e.T22701558A93836378. DOI: https://dx.doi.org/10.2305/IUCN.UK.2016-3.RLTS. T22701558A93836378.en

BRASIL, 1981. Ministério das Minas e Energia. Secretaria Geral. Projeto RADAMBRASIL. Folha SC. 22. Tocantins: Geologia, geomorfologia, pedologia, vegetação e uso potencial da terra: 1-524. Rio de Janeiro.

CASTRO, A. M. G., F. L. TONANI \& S. M. V. LIMA, 2019. Desafios para o desenvolvimento do complexo agroindustrial do eucalipto para agroenergia na região Norte do Brasil. Brazilian Journal of Development 5(9): 14292-14320. DOI: https://doi.org/10.34117/ bjdv5n9-045

CHAGAS-JUNIOR, A., G. D. EDGECOMBE \& A. MINELLI, 2008. Variability in trunk segmentation in the centipede order Scolopendromorpha: a remarkable new species of Scolopendropsis Brandt (Chilopoda: Scolopendridae) from Brazil. Zootaxa 1888(1): 36-46. DOI: https://doi.org/10.11646/zootaxa.1888.1.2 
DAMBRÓS, L. A., L. C. OLIVEIRA-FILHO, E. C. FREIRE, J. P. D. S. LIMA, J. D. A. PEREIRA, S. S. SILVA \& J. R. R. FORZANI, 2005. Inventário florestal e levantamento florístico, norte do estado do Tocantins. Zoneamento Ecológico-Econômico Estudo de Flora e Fauna, Norte do Tocantins, Escala 1:250.000. Secretaria Estadual de Planejamento e Meio Ambiente/SEPLAN, Palmas.

DORNAS, T., L. RAMOS, R. T. PINHEIRO \& M. O. BARBOSA, 2012. Importantes e inéditos registros de aves para o ecótono Amazônia/Cerrado no centro norte do estado do Tocantins: implicações biogeográficas e extensão de distribuição geográfica de aves amazônicas. Revista Brasileira de Ornitologia 20(2): 119-127.

DORNAS, T., 2016a. WA2294197, Herpsilochmus sellowi Whitney \& Pacheco, 2000. Wiki Aves - A Enciclopédia das Aves do Brasil. Disponível em: http://www.wikiaves.com/2294197. Acesso em: 6 agosto 2020.

DORNAS, T., 2016b. WA2294070, Herpsilochmus sellowi Whitney \& Pacheco, 2000. Wiki Aves - A Enciclopédia das Aves do Brasil. Disponível em: http://www.wikiaves.com/2294070. Acesso em: 6 agosto 2020.

DORNAS, T., 2016c. Aves da Amazônia tocantinense e regiões ecotonais: composição e riqueza, endemismos, biogeografia e conservação. Tese (Doutorado em Biodiversidade e Conservação, Rede Bionorte em Biotecnologia e Biodiversidade) - Museu Paraense Emílio Goeldi, Universidade Federal do Pará, Belém.

HAIDAR, R. F., J. M. F. FAGG, J. R. R. PINTO, R. R. DIAS, G. DAMASCO, L. C. R. SILVA \& C. W. FAGG, 2013. Florestas estacionais e áreas de ecótono no estado do Tocantins, Brasil: parâmetros estruturais, classificação das fitofisionomias florestais e subsídios para conservação. Acta Amazonica 43(3): 261-290. DOI: https://doi.org/10.1590/S0044-59672013000300003

INSTITUTO BRASILEIRO DE GEOGRAFIA E ESTATÍSTICA (IBGE), 2007. Mapas temáticos pedologia do Tocantins: sistema de projeção policônica, escala 1:1.000.000: 1. ed. Coordenação de Recursos Naturais e Estudos Ambientais, Rio de Janeiro. Disponível em: https://mapas.ibge.gov.br/tematicos/solos/. Acesso em: 24 março 2020.

INSTITUTO BRASILEIRO DE GEOGRAFIA E ESTATÍSTICA (IBGE), [s. d.]. Cartas e mapas. Disponível em: https://www. ibge.gov.br/geociencias/cartas-e-mapas.html. Acesso em: 24 março 2020.

INSTITUTO CHICO MENDES DE CONSERVAÇÃO DA BIODIVERSIDADE (ICMBio), 2013. Aplicação de critérios e categorias da IUCN na avaliação da fauna brasileira. Coordenação de Avaliação do Estado de Conservação da Biodiversidade, Instituto Chico Mendes de Biodiversidade. Versão 2.0. Disponível em: https:// www.icmbio.gov.br/portal/images/stories/biodiversidade/faunabrasileira/avaliacao-do-risco/apostila_aplicacao_criterios_categorias_ UICN_versao_2.0.pdf. Acesso em: 23 marçō 2020.
INSTITUTO NACIONAL DE PESQUISAS ESPACIAIS (INPE), 2018. Portal do monitoramento de queimadas e incêndios. Programa Queimadas. Disponível em http://www.inpe.br/queimadas/. Acesso em: 5 abril 2020.

INTERNATIONAL UNION FOR CONSERVATION OF NATURE (IUCN), (2019). IUCN Standards and Petitions Committee. Guidelines for Using the IUCN Red List Categories and Criteria. Version 14. Prepared by the Standards and Petitions Committee. Disponível em: http://www.iucnredlist.org/documents/ RedListGuidelines.pdf. Acesso em: 22 março 2020.

MINISTÉRIO DO MEIO AMBIENTE (MMA), 2000. Lei Federal $n^{\circ}$ 9.985/00, de 18 de julho de 2000. Regulamenta o art. 225, $\S 1^{\circ}$, incisos I, II, III e VII da Constituição Federal, institui o Sistema Nacional de Unidades de Conservação da Natureza e dá outras providências. Diário Oficial da União, Brasília, 19 de julho 2000. Disponível em: http://www.planalto.gov.br/ccivil 03/LEIS/L9985. htm. Acesso em: 22 março 2020.

MINISTÉRIO DO MEIO AMBIENTE (MMA), 2014. Portaria $n^{\circ}$ 444, de 17 de dezembro de 2014. Lista Nacional Oficial de Espécies da Fauna Ameaçadas de Extinção. Diário Oficial da República Federativa do Brasil, Brasília, DF, n 245, 18 de dezembro de 2014. Seção 1, p. 122-126. Disponível em: https://www. icmbio.gov.br/cepsul/images/stories/legislacao/Portaria/2014/p_ mma 4442014 lista esp\%C3\%A9cies ame\%C3\%A7adas

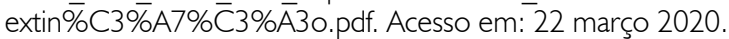

MOREIRA, R. S., 2017. Análise temporal do uso e cobertura da terra e diversidade de aves como subsídios para a conservação da biodiversidade na Área de Proteção Ambiental do Lago de Palmas, Tocantins. Dissertação (Mestrado em Ecologia de Ecótonos) - Universidade Federal do Tocantins, Porto Nacional.

OliveirA, P. A., J. M. PELÚZIO \& W. G. SILVA, 2019 Análise das mudanças na vegetação nativa da APA Lago de Palmas. Ciência Florestal 29(3): 1376-1388. DOI: https://doi. org/10.5902/1980509834424

OLMOS, F., G. ARBOCZ, J. F. PACHECO \& R. R., DIAS, 2004. Estudo de flora e fauna do norte do estado do Tocantins. In: R. R. DIAS (Org.): Projeto de gestão ambiental integrada Bico do Papagaio: 1-130. Zoneamento Ecológico Econômico/SEPLAN, Palmas.

PACHECO, J. F. \& F. OLMOS, 2005. Birds of a Latitudinal Transect in the Tapajós-Xingu Interfluvium, eastern Brazilian Amazônia. Ararajuba 13(1): 29-46.

PINTO, L. M. C., 2014. Luzimangues: uma "nova cidade" na periferia de Palmas? Arquitextos Vitruvius 164.02: 1-10.

RODRIGUES, M. T., D. T. PAVAN \& F. F. CURCIO, 2007. Two new species of lizards of the genus Bachia (Squamata, Gymnophthalmidae) from Central Brazil. Journal of Herpetology 41: 545-553. 
SANTOS, M. P. D., L. F. SILVEIRA \&J. M. C. SILVA, 2011. Birds of Serra do Cachimbo, Pará State, Brazil. Revista Brasileira de Ornitologia 19(2): 244-259.

SECRETARIA DA FAZENDA E PLANEJAMENTO (SEFAZ), 2019. Estado do Tocantins, áreas de uso legal restrito e potenciais à conservação ambiental - tabelas e mapas: 2. ed.: 1-56. Gerência de Zoneamento Territorial, Palmas.

SECRETARIA E PLANEJAMENTO DO ESTADO DO TOCANTINS (SEPLAN), 2012. Atlas do Tocantins: subsídios ao planejamento da gestão territorial: 6. ed.: 1-80. SEPLAN, Palmas.

SERVIÇO GEOLÓGICO DO BRASIL (CPRM), [s. d.]. Disponível em: http://geosgb.cprm.gov.br/. Acesso em: 22 março 2020.

SOUZA, O. M. N., E. COLLICCHIO, E. Q. PEREIRA \& M. I. R. AZEVEDO, 2015. Zoneamento edafoclimático para o Eucalyptus urophylla no estado do Tocantins. Desafios - Revista Interdisciplinar da Universidade Federal do Tocantins 1(2): 120-134. DOI: https:// doi.org/10.20873/uft.2359-3652.2015v1n2p120

TOCANTINS, 2005. Lei no 1.560, de 5 de abril de 2005. Institui o Sistema Estadual de Unidades de Conservação da Natureza, SEUC, e estabelece critérios e normas para a criação, implantação e gestão das unidades que o constituem. Disponível em: https://central3.to.gov. br/arquivo/225866/. Acesso em: 25 março 2020.
TOCANTINS, 2020. Plano de Ação Territorial para Conservação de Espécies Ameaçadas de Extinção do Território Cerrado Tocantins. Sumário Executivo. Projeto Pró-Espécies: Todos contra a extinção. Instituto Natureza do Tocantins (Naturatins), Palmas, Tocantins. Disponível em: https://central3.to.gov.br/ arquivo/536142/. Acesso em: 24 março 2021.

WHITNEY, B. M., J. F. PACHECO, D. R. C. BUZZETTI \& R. PARRINI, 2000. Systematic revision and biogeography of the Herpsilochmus pileatus complex, with description of a new species from northeastern Brazil. The Auk 117(4): 869-891. DOI: https:// doi.org/10.1093/auk/117.4.869

WIKIAVES, [s. d.]. Disponível em: https://www.wikiaves.com.br/. Acesso em: 22 março 2020.

XENO-CANTO FOUNDATION, [s. d.]. Disponível em: https:// www.xeno-canto.org/. Acesso em: 22 março 2020. 